\title{
Penetration electric fields observed at middle and low latitudes during the 22 June 2015 geomagnetic storm
}

\author{
Kumiko K. Hashimoto ${ }^{1 *}$ (D), Takashi Kikuchi ${ }^{2}$, Ichiro Tomizawa ${ }^{3}$, Keisuke Hosokawa ${ }^{4}$, Jaroslav Chum ${ }^{5}$, \\ Dalia Buresova ${ }^{5}$, Masahito Nose ${ }^{2}$ and Kiyokazu Koga ${ }^{6}$
}

\begin{abstract}
Prompt penetration electric fields were detected during the intense geomagnetic storm on 22 June, 2015 by the HF Doppler sounders at middle and low latitudes; Prague (Czech Republic), litate, Oarai, Onna (Japan), and Zhongli (Republic of China). The storm was initiated by the storm sudden commencement (SC) at 1833 UT, immediately followed by the main phase with the minimum SYM-H of - 139 nT at 2017 UT. The convection electric field was found to be up to $5.1 \mathrm{mV} / \mathrm{m}$ at low latitudes, which is enough to cause ionospheric disturbances such as the enhancement of the total electron content, equatorial ionization anomaly and so on. The electric fields of the SC and main phase are westward in the night (0330 MLT), while eastward in the evening (1930 MLT). The main phase electric field intensified the eastward equatorial electrojets (EEJ) at Huancayo in South America on the dayside (1330 MLT) and the westward EEJ on the nightside at Guam in the western Pacific (0330 MLT) and Tirunelveli in India (00 MLT). The eastward direction of the evening-time electric field agrees with a feature of the evening anomaly of the penetration electric field, while the intensity is suppressed because of the sunlit condition in the evening in the summer solstice. The sudden northward turning of the interplanetary magnetic field (IMF) caused a transition from the main phase to the recovery phase, when the EEJ turned into the counterelectrojet (CEJ). It was found that the HF Doppler sounders detected an impulsive eastward overshielding electric field at 2005 UT on the nightside during the northward IMF-driven CEJ with the duration of $17 \mathrm{~min}$ and intensity of $8.0 \mathrm{mV} / \mathrm{m}$ at litate $(0500 \mathrm{MLT})$ and $11.8 \mathrm{mV} / \mathrm{m}$ at Prague (2130 MLT). The impulsive overshielding electric field was accompanied by the anti-sunward plasma flows at middle latitude $\left(50^{\circ}-60^{\circ}\right.$ GML) equatorward of the dusk sunward convection as observed with SuperDARN, which signifies intensification of the Region-2 field-aligned currents at the flow reversal. Substorm signatures are identified with intensified westward auroral electrojet and magnetic dipolarization as detected by the geosynchronous orbit satellite, ETS-VIII. Consequently, the stormtime substorm may provide strong overshielding electric fields to the middle latitude ionosphere on the nightside.
\end{abstract}

Keywords: HF Doppler sounder, Penetration electric field, Convection electric field, Overshielding electric field, Geomagnetic storm, Middle latitude ionosphere

\section{Introduction}

Storm time penetration electric fields at low latitude ionosphere have been examined by means of ground-based

\footnotetext{
*Correspondence: hashi@geosci.jp

1 School of Agriculture, Kibi International University, 370-1, Shichi-Sareo, Minamiawaji, Hyogo, Japan

Full list of author information is available at the end of the article
}

magnetometers, radars and low Earth orbiting spacecrafts (e.g., Rastogi 1977; Fejer et al. 2007; Kil et al. 2007; Kikuchi et al. 2008; Huang 2015; Astafyeva et al. 2016). When the interplanetary magnetic field (IMF) turns southward, the dynamo that generates the convection electric field and Region-1 field-aligned currents (FACs) is activated around the cusp region in the 
outer magnetosphere (Tanaka 1995, 2007). The electric potential and currents are transmitted to the polar ionosphere and then toward the equator by means of the zeroth-order transverse magnetic $\left(\mathrm{TM}_{0}\right)$ mode waves propagating at the speed of light in the Earth-ionosphere waveguide (Kikuchi et al. 1978; Kikuchi 2014), disseminating the positive and negative potentials to the global ionosphere. The potential difference provides ionospheric electric fields responsible for the motion of plasma in the F-region and DP2-type Hall currents in the E-region.

The equatorial electrojets (EEJs) on the dayside have been examined for many years in studies of the prompt penetration electric fields from high latitudes to low latitudes (Rastogi 1977; Kikuchi et al. 1996; Hashimoto et al. 2011). The penetration electric field suffers severe geometrical attenuation to be less than one tenth of the source intensity at low latitudes. However, the Pedersen currents are intensified at the dayside equator (Kikuchi et al. 1978), because of the anomalously high Cowling conductivity of the equatorial E-region (Hirono 1952). Thus, the magnetometer deployed at the magnetic equator on the dayside well detects the penetration electric field. In other words, the daytime equatorial ionosphere works as a sensitive antenna to the penetration electric field.

During the geomagnetic storms, the $\mathrm{H}$-component of the magnetic field decreases considerably at middleequatorial latitudes, which is caused by the ring current driven by the dawn-to-dusk convection electric field (Ebihara and Ejiri 2000). However, the stormtime magnetic fields are superposed by disturbances due to the ionospheric DP2 currents driven by the dawn-to-dusk convection electric field even at middle latitude (Wilson et al. 2001) and at the equator (Kikuchi et al. 2008; Tsuji et al. 2012). During the storm main phase, the auroral electrojet (AEJ) expands to the middle latitude as low as $55^{\circ} \mathrm{GML}$ (geomagnetic latitude) (Feldstein et al. 1997; Kikuchi et al. 2008). At the equator, the convection electric field intensifies the eastward EEJ on the dayside during the main phase, while the EEJ decreases to be westward EEJ, i.e., counterelectrojet (CEJ) due to the overshielding during the recovery phase (Kikuchi et al. 2008).

In contrast to the convection electric field associated with the Region-1 FACs, the dusk-to-dawn overshielding electric field originates from the Region-2 FACs that is generated by the dynamo in the inner magnetosphere as a result of development of the magnetospheric plasma convection (Vasyliunas 1972). Convection reduction due to a northward turning of the IMF is one of the possible causes for the overshielding (Kelley et al. 1979). It has also been reported that the overshielding electric field becomes dominant at low latitudes, when the AEJ moves poleward rapidly at the beginning of the storm recovery phase (Kikuchi et al. 2008) and the Region-2 FACs intensify at the substorm expansion (Wei et al. 2009; Hashimoto et al. 2011, 2017).

Direct measurements of the stormtime electric fields have been carried out with the incoherent scatter radar (ISR) in Jicamarca (Fejer et al. 2007; Huang et al. 2010) and low Earth orbiting spacecrafts; DMSP (Burke et al. 2000; Huang et al. 2010), C/NOFS and ROCSAT-1 (Kil et al. 2007; Huang 2015; Zhang et al. 2017). In major storms, the ISR detected the electric field with magnitude greater than $3 \mathrm{mV} / \mathrm{m}$ at the equator (Fejer et al. 2007). However, only a few observations of stormtime electric fields have been reported from the middle and low latitudes, because of sparse facilities at these latitudes (Blanc et al. 1977). No direct measurements of the penetration electric fields have been reported even for the recent major storm on 22 June, 2015, although quite a few papers have clarified effects of the penetration electric fields on the equatorial plasma bubbles in the postsunset (Cherniak et al. 2019), disturbances in the EEJ (Singh and Sripathi 2017; Astafyeva et al. 2018), and ionospheric and thermospheric density variations (Astafyeva et al. 2016; 2017; Ngwira et al. 2019). The present paper reports direct measurements of the penetration electric fields at middle and low latitudes, using the HF Doppler sounders in Europe and western Pacific zones.

The HF Doppler sounders measure Doppler frequency deviations of the HF radio signal reflected from the ionospheric F-region caused by the vertical motion due to the ExB drift of plasma (Davies et al. 1962). The HF Doppler sounder is sensitive to the electric field of short period (1-10 $\mathrm{min}$ ) disturbances such as the geomagnetic sudden commencement (SC) and geomagnetic pulsations (Davies et al. 1962; Kikuchi et al. 1985, 2016; Alperovich et al. 1991; Motoba et al. 2004; Baddeley et al. 2005) and is capable of detecting electric fields of substorms (20 min) (Tsutsui et al. 1988; Hashimoto et al. 2017) and quasi-periodic DP2 fluctuations (30 min) (Reddy et al. 1994; Abdu et al. 1998). Hashimoto et al. (2017) detected eastward overshielding electric field on the nightside that occurred simultaneously with the dayside CEJ during substorms. The results showed that the overshielding electric field is the dusk-to-dawn electric field associated with the Region-2 FACs.

From these observations, we would expect to detect the stormtime electric fields with longer time scales by means of the HF Doppler sounders at middle and low latitudes. In this paper, we report our finding that strong stormtime electric fields were detected simultaneously in Japan and Czech Republic in the post-midnight and evening hours, respectively, during the major storm on 22 June, 2015. During the main phase, the electric field was westward in 
the post-midnight with the eastward EEJ on the dayside, meeting the dawn-to-dusk convection electric field. In the evening sector, on the other hand, the electric field manifested the evening anomaly with the same direction as on the dayside. In the beginning of the recovery phase, the EEJ turned into the CEJ because of the northward turning of the IMF. We found that an impulsive eastward overshielding electric field with duration of $17 \mathrm{~min}$ was observed during the northward IMF-driven CEJ simultaneously in Japan and Czech Republic on the nightside. We will show substorm signatures during the impulsive overshielding and suggest that the stormtime substorm may provide significant overshielding electric fields to the middle latitude ionosphere.

\section{HF Doppler sounders and magnetometer networks}

The HF Doppler sounders have been used to detect the motion of the reflection height of the HF radio signal, providing the ionospheric electric fields during short period disturbances like the geomagnetic sudden commencements (Kikuchi et al. 1985, 2016; Sastri et al. 2000), geomagnetic pulsations (Pc5, Pi2) (Alperovich et al. 1991; Baddeley et al. 2005; Pilipenko et al. 2013), quasiperiodic DP2 magnetic field fluctuations (Abdu et al. 1998; Sastri et al. 2000) and substorms (Tsutsui et al. 1988; Hashimoto et al. 2017).

The observed Doppler shifts result from vertical velocities caused by the ExB drift motion of ionospheric plasma. Since the penetration electric field propagates almost instantaneously to the global ionosphere (Kikuchi et al. 1996), we identify the penetration electric field from ionospheric motions with no time difference in two local time zones. In the present paper, the electric fields of geomagnetic storms are observed at multi-points in Japan (MLT $=\mathrm{UT}+9)$, Prague, Czech Republic $(\mathrm{MLT}=\mathrm{UT}+1)$, and Zhongli, Republic of China (MLT $=\mathrm{UT}+8)$ as indicated in red in Fig. 1.

The Japanese sounders consist of one transmitter at the Center for Space Science and Radio Engineering, University of Electro-Communications, Chofu, Tokyo, with frequencies of 5.006 and $8.006 \mathrm{MHz}$, and three receivers at Oarai, Ibaraki; Iitate, Fukushima; and Onna, Okinawa; $120 \mathrm{~km}, 250 \mathrm{~km}$, and $1500 \mathrm{~km}$ away from the transmitter, respectively (Table 1 ). The HF Doppler sounders in Prague and Zhongli consist of three transmitters ( $\mathrm{Tx} 1, \mathrm{Tx} 2, \mathrm{Tx} 3)$ and one receiver with the sounding frequencies of $3.59 \mathrm{MHz}$ (Prague) and 6.57 MHz (Zhongli) (see details in Laštovička and Chum 2017; Chum et al. 2018). The Doppler frequency data from one of the transmitters, Tx2, are analyzed in this study. The data in Japan are sampled every $10 \mathrm{~s}$ and are made smooth through the running average over $60 \mathrm{~s}$ to suppress the short-period fluctuations and impulsive noises. The data in Zhongli and Prague are digitized every $30 \mathrm{~s}$.

If the radio wave of HF Doppler reflects in the F-region, where the plasma is magnetized, then the eastward electric field $E$ can be estimated from the observed Doppler shift $\Delta f$ caused by vertical plasma motion owing to $\boldsymbol{E} \times \boldsymbol{B}$ drift ( $\boldsymbol{E}$ : electric field intensity and $\boldsymbol{B}$ : geomagnetic flux density) as:

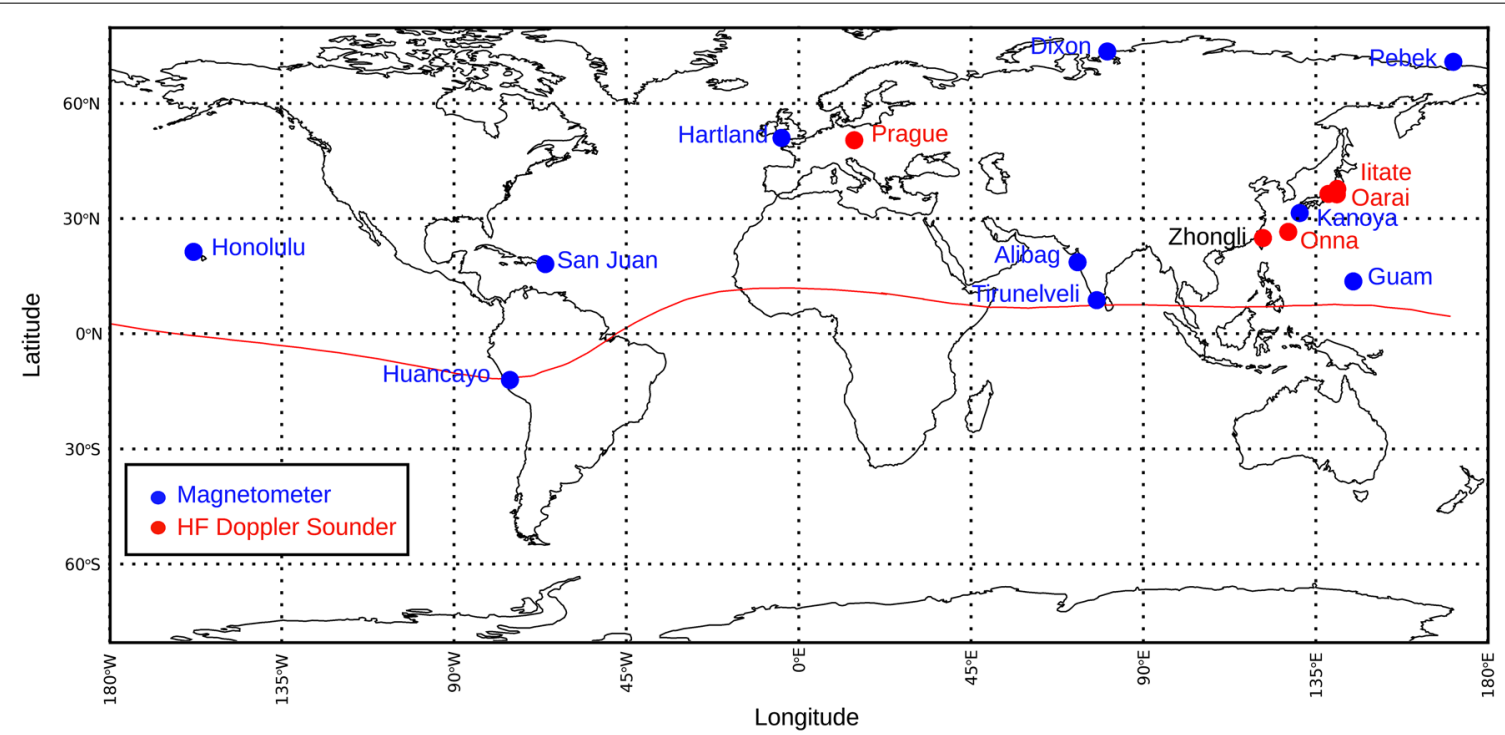

Fig. 1 Maps of the HF Doppler sounders in Japan, Czech Republic and Republic of China (red) and of magnetometers at high-equatorial latitudes (blue). The dip-equator is shown with the red curve. Details of the stations are listed in Table 1 
Table 1 List of HF Doppler sounders in Japan, Czech Republic and Republic of China

\begin{tabular}{|c|c|c|c|c|c|c|c|c|}
\hline \multirow[t]{2}{*}{ Abbreviation } & \multirow[t]{2}{*}{ Station name } & \multirow[t]{2}{*}{ Country } & \multicolumn{2}{|c|}{$\begin{array}{l}\text { Geographic coordinate } \\
\text { (deg) }\end{array}$} & \multicolumn{2}{|c|}{$\begin{array}{l}\text { Geomagnetic coordinate } \\
\text { (deg) }\end{array}$} & \multirow[t]{2}{*}{ Distance (km) } & \multirow{2}{*}{$\begin{array}{l}\text { Elevation } \\
\text { angle } \\
\text { (deg) }\end{array}$} \\
\hline & & & Latitude & Longitude & Latitude & Longitude & & \\
\hline $\mathrm{CHF}$ & Chofu & Japan & 35.65 & 139.55 & 27.13 & 209.15 & - & - \\
\hline$\| \mathrm{T}$ & litate & Japan & 37.68 & 140.79 & 29.23 & 210.04 & 250 & 67.4 \\
\hline ORI & Oarai & Japan & 36.33 & 140.59 & 27.89 & 210.02 & 120 & 78.7 \\
\hline ONN & Onna & Japan & 26.51 & 127.87 & 17.24 & 199.18 & 1504 & 21.8 \\
\hline PRG & Prague & Czech & 50.04 & 14.48 & 49.37 & 98.51 & 7 & 89.3 \\
\hline ZHG & Zhongli & Taiwan & 24.97 & 121.19 & 15.40 & 192.99 & 82 & 82.2 \\
\hline
\end{tabular}

$$
E=-\frac{c B}{2 f \cos I \sin \theta} \Delta f
$$

where $f, c, I$ and $\theta$ are the radio wave frequency, light speed, inclination angle of the geomagnetic field, and elevation angle of the radio path, respectively (Davies et al. 1962). By applying parameters in Table 1, the electric field is derived from the HF Doppler frequency as below:

1. Iitate (N29.23 $\mathrm{GML})$

$$
\begin{aligned}
& f=5.006[\mathrm{MHz}] \quad d=250[\mathrm{~km}] \\
& E[\mathrm{mV} / \mathrm{m}]=-2.16 \Delta f[\mathrm{~Hz}],
\end{aligned}
$$

2. Oarai (N27.89 $\mathrm{GML})$

$$
\begin{aligned}
& f=5.006[\mathrm{MHz}] \quad d=120[\mathrm{~km}] \\
& E[\mathrm{mV} / \mathrm{m}]=-1.92 \Delta f[\mathrm{~Hz}],
\end{aligned}
$$

3. Onna (N17.24 GML)

$$
\begin{aligned}
& f=8.006[\mathrm{MHz}] \quad d=1504[\mathrm{~km}] \\
& E[\mathrm{mV} / \mathrm{m}]=-2.46 \Delta f[\mathrm{~Hz}],
\end{aligned}
$$

4. Zhongli (N15.40 GML)

$$
\begin{aligned}
& f=6.57[\mathrm{MHz}] \quad d=82[\mathrm{~km}] \\
& E[\mathrm{mV} / \mathrm{m}]=-1.12 \Delta f[\mathrm{~Hz}],
\end{aligned}
$$

5. Prague (N49.37 $\mathrm{GML})$

$$
\begin{aligned}
& f=3.59[\mathrm{MHz}] \quad d=7[\mathrm{~km}] \\
& E[\mathrm{mV} / \mathrm{m}]=-4.39 \Delta f[\mathrm{~Hz}] .
\end{aligned}
$$

In order to confirm that the HF Doppler frequency variations are caused by the penetration electric field, we examined the EEJ which is intensified during geomagnetic storms by the magnetospheric electric field penetrating to the equator through the polar ionosphere (Kikuchi et al. 2008; Tsuji et al. 2012). The EEJ is derived from the difference between the $\mathrm{H}$-components at low latitude and dip-equator under an assumption that the magnetospheric currents equally affect the low latitude and equator. We obtained the EEJs in the three local time zones of Huancayo (HUA)-San Juan (SJG) in American sector, Guam (GUA)-Kanoya (KNY) in the western Pacific and Tirunelveli (TIR)-Alibag (ABG) in India (Table 2) with the sampling time of $1 \mathrm{~min}$. The data from HUA, SJG, GUA, KNY were downloaded from the INTERMAGNET website (http://www.inter magnet.org), and magnetic field data at ABG and TIR are from SuperMAG (Gjerloev 2012; http://supermag. jhuapl.edu). It should be mentioned that quiet time daily variations are not subtracted from the disturbed day variations, because the duration of the main phase was $1.3 \mathrm{~h}$, during which the daily variation can be neglected compared to the main phase variations.

To detect the ionospheric currents flowing in the north-south direction from high latitude to the equator, we used the Y-component of the magnetic field from the INTERMAGNET stations at middle latitudes, Hartland (HAD), UK and Honolulu (HON), Hawaii (Table 2). Furthermore, we used the magnetometer data from Dixon (DIK) and Pebek (PBK) of the THEMIS magnetometer network located at auroral latitudes in Russia (Table 2) to show substorm activities on the nightside. The THEMIS ground magnetometer data are obtained from the coordinated data analysis web (https ://cdaweb.sci.gsfc.nasa.gov).

\section{Geomagnetic storm on 22 June, 2015 Solar wind data and geomagnetic indices}

In this paper, we focus on the geomagnetic storm that started at 1833 UT on 22 June, 2015 and turned into the recovery at 2007 UT on the same day. The storm (hereafter referred to as 22 June storm) is followed by another development of the ring current on 23 June such that the 22-23 June storm goes into the recovery phase in the beginning of 23 June (Piersanti et al. 2017). However, we focus on the 22 June storm, since the HF 
Table 2 List of the INTERMAGNET, SuperMAG, and THEMIS magnetometer stations

\begin{tabular}{|c|c|c|c|c|c|c|}
\hline \multirow[t]{2}{*}{ Abbreviation } & \multirow[t]{2}{*}{ Station name } & \multirow[t]{2}{*}{ Country } & \multicolumn{2}{|c|}{ Geographic coordinate (deg) } & \multicolumn{2}{|c|}{ Geomagnetic coordinate (deg) } \\
\hline & & & Latitude & Longitude & Latitude & Longitude \\
\hline \multicolumn{7}{|l|}{ INTERMAGNET } \\
\hline GUA & Guam & USA & 13.59 & 144.87 & 5.76 & 216.50 \\
\hline HAD & Hartland & UK & 51.0 & 355.52 & 53.48 & 80.19 \\
\hline HON & Honolulu & USA & 21.32 & 202.00 & 21.65 & 270.82 \\
\hline HUA & Huancayo & Peru & -12.04 & 284.68 & -2.28 & 357.36 \\
\hline KNY & Kanoya & Japan & 31.42 & 130.88 & 22.30 & 201.62 \\
\hline SJG & San Juan & USA & 18.11 & 293.85 & 27.62 & 6.95 \\
\hline \multicolumn{7}{|l|}{ SuperMag } \\
\hline$A B G$ & Alibag & India & 18.64 & 72.87 & 10.47 & 146.89 \\
\hline $\mathrm{TIR}$ & Tirunelveli & India & 8.7 & 77.80 & 0.20 & 150.79 \\
\hline \multicolumn{7}{|l|}{ THEMIS } \\
\hline DIK & Dixon & Russia & 73.53 & 80.70 & 69.06 & 156.26 \\
\hline PBK & Pebek & Russia & 70.08 & 170.90 & 65.58 & 231.11 \\
\hline
\end{tabular}

Doppler sounders detected the stormtime convection and overshielding electric fields on 22 June. Thus, the storm of our concern goes into the recovery phase at 2007 UT on 22 June. Figure 2a shows three components of the IMF (Bx, By, and Bz), velocity (Vsw), and ion density (Ion $\mathrm{N}$ ) of the solar wind observed by ACE at the Lagrangian Point L1 during the time interval of the storm. The time of the ACE data is shifted by $35 \mathrm{~min}$ so that we can see the correspondence between the sudden increases in the solar wind density and speed and the geomagnetic sudden commencement (SC) on the ground. Figure $2 \mathrm{~b}$ shows the SYM-H and ASY-H geomagnetic indices from the WDC for Geomagnetism, Kyoto. The sudden increase of the solar wind dynamic pressure caused the SC at 1833 UT on 22 June, 2015. The IMF Bz was slightly negative with $-2.1 \mathrm{nT}$ as averaged over $1 \mathrm{~h}$ before the arrival of the ICME. The IMF Bz then dramatically decreased to $-23.6 \mathrm{nT}$ at $1833 \mathrm{UT}$ and reached the minimum value of $-39.5 \mathrm{nT}$ at 1925 UT concurrently with sudden increases in the density and velocity. The average value of the southward IMF was - $29.0 \mathrm{nT}$ over the time interval of $72 \mathrm{~min}$ until the northward turning of the IMF Bz at 1945 UT. The solar wind velocity abruptly increased from 475 to $704 \mathrm{~km} / \mathrm{s}$ and the density jumped from 25 to $44 / \mathrm{cc}$. Subsequently, the density gradually decreased to 25/cc at 1920 UT. As can be seen in Fig. 2b, the SYM-H abruptly increased at 1833 UT by an amount of $110 \mathrm{nT}$, followed by the steep decrease by an amount of 230 nT until 2015 UT, indicating that the storm ring current developed immediately after the $\mathrm{SC}$, because of the strong southward IMF accompanying the increases in the solar wind speed and density.

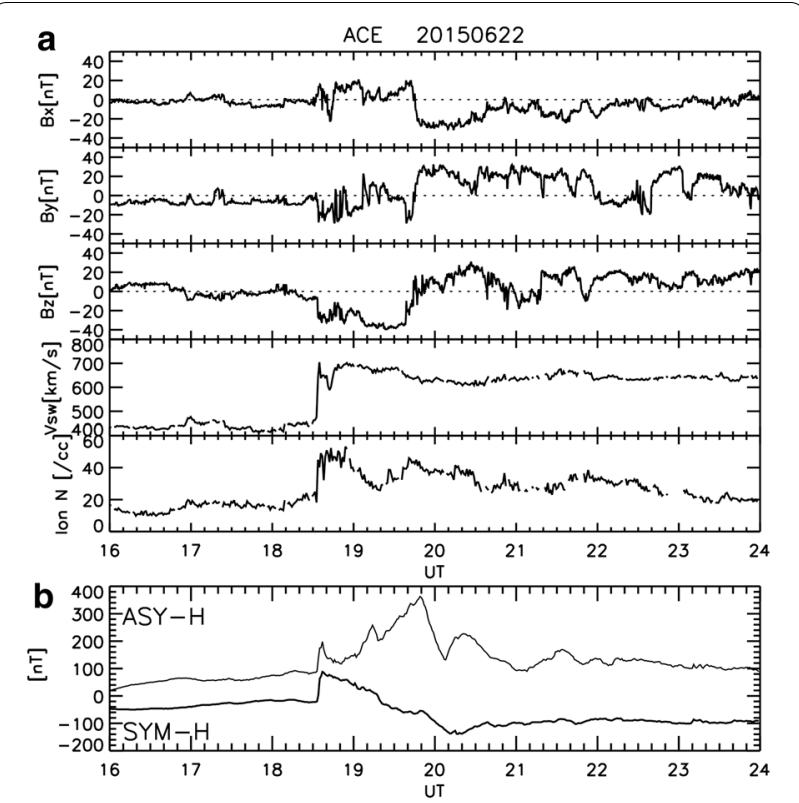

Fig. 2 a (From the top) Three components (Bx, By, Bz) of the interplanetary magnetic field (IMF), velocity (Vsw) and ion density (Ion N) of the solar wind observed by ACE at the Lagrangian point-1 (L1) during the geomagnetic storm on 22 June, 2015. The time of the ACE data is shifted by $35 \mathrm{~min}$ so that we can see the correspondence between the sudden increases in the solar wind density and speed and the geomagnetic sudden commencement on the ground (SC). $\mathbf{b}$ SYM-H and ASY-H geomagnetic indices from WDC C2 Kyoto

\section{Equatorial electrojets during the storm main phase}

Figure 3 a shows the X-component of the magnetic field at the low latitude, San Juan (SJG) and equator, Huancayo (HUA) in the American zone (Table 2). The storm occurred when the stations were located in the afternoon 


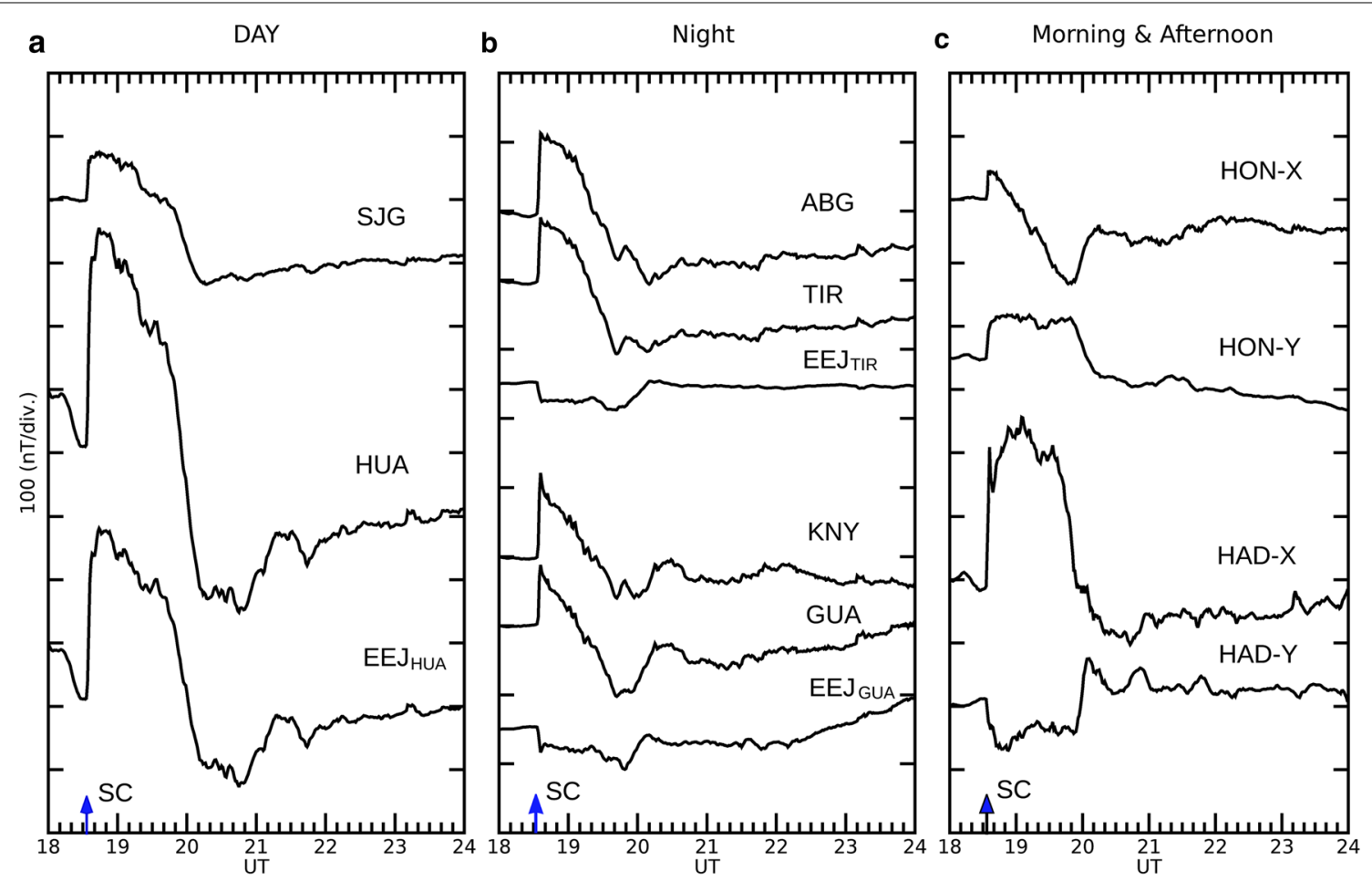

Fig. 3 a X-component of the magnetic fields at the low latitude (San Juan, SJG) and equator (Huancayo, HUA) in the American zone located on the dayside (1330 MLT) when the geomagnetic storm occurred on 22 June, 2015. The EEJ $\mathrm{HUA}_{\mathrm{A}}$ denotes the equatorial electrojet defined as the difference between $X_{\text {HUA }}$ and $X_{\text {SJG }}$. b Same parameters for the low latitude (Alibag, ABG) and equator (Tirunelveli, TIR) in the Indian zone located in the midnight (00-02 MLT) and for the low latitude (Kanoya, KNY) and equator (Guam, GUA) in the western Pacific zone, located in the pre-dawn (03-05 MLT). c X and Y components of the magnetic field at middle latitudes, Honolulu (HON) in the morning (09 MLT) and at Hartland (HAD) in the evening (19MLT)

sector (1400 MLT at $1900 \mathrm{UT})$. Both the $\mathrm{X}_{\mathrm{HUA}}$ and $\mathrm{X}_{\mathrm{SJG}}$ started to increase at $1833 \mathrm{UT}$, reaching the peak of the amplitude $80 \mathrm{nT}$ at $1836 \mathrm{UT}$ at SJG, whereas reaching the peak of $350 \mathrm{nT}$ at $1843 \mathrm{UT}$ at HUA. The enhanced $\mathrm{X}_{\mathrm{HUA}}$ was followed by the steep decrease over the period of 1943-2010 UT, when the storm turned into the recovery phase because of the northward turning of the IMF. The EEJ turned into the counterelectrojet (CEJ), indicating the overshielding associated with the convection reduction at the equator (Kelley et al. 1979). It should be noted that the rapid decrease in the ASY-H at 1950 UT (Fig. 2b) is also caused by the northward turning of the IMF. The reduction of $\mathrm{X}_{\mathrm{HUA}}$ was $580 \mathrm{nT}$ from the peak of the main phase, while the $\mathrm{X}_{\mathrm{SIG}}$ decreased by $200 \mathrm{nT}$. The enhancement of the main phase variations at HUA should be due to the EEJ and CEJ, caused by the dawn-to-dusk convection electric field and overshielding electric field associated with the northward turning of the IMF. The EEJ is obtained as the difference between $\mathrm{X}_{\mathrm{HUA}}$ and $\mathrm{X}_{\mathrm{SJG}}$ with magnitude of $380 \mathrm{nT}$ under an assumption that the storm ring currents contribute equally to both stations. The main phase EEJ has been detected by the Swarm satellite as the negative magnetic deflections above the EEJ (Astafyeva et al. 2016) and the CEJ at $X_{\mathrm{HUA}}$ was shown by Ngwira et al. (2019). It is remarkable that the geomagnetic storm is enhanced at the dayside equator with magnitude three times as large as the storm at low latitude in a similar way to the major storm on 6 November 2001 (Kikuchi et al. 2008). The equatorial enhancement of the geomagnetic storm is caused by both effects of the EEJ and CEJ superposed on the magnetic fields due to the ring current. Therefore, the stormtime EEJ can produce even greater magnetic disturbances than those by the stormtime ring current.

Figure $3 \mathrm{~b}$ shows the $\mathrm{X}$-components from low and equatorial latitudes, Alibag (ABG) and Tirunelveli (TIR) in the Indian zone and Kanoya (KNY) and Guam (GUA) in the western Pacific zone. The storm main phase occurred, when ABG and TIR were located in the midnight (00-02 MLT) and KNY and GUA were located before dawn (03$05 \mathrm{MLT})$. Unlike the gradual decrease in $\mathrm{X}_{\mathrm{SIG}}$ at the dayside low latitude (Fig. 3a), the X-component at all of the four stations on the nightside (Fig. 3b) decreased steeply immediately after the SC and reached the minima at 1940 
UT. The asymmetric development is due to the partial ring currents on the nightside that is commonly observed during the storm main phase (Tsuji et al. 2012).

The EEJs derived from $\mathrm{X}_{\mathrm{TIR}}$ and $\mathrm{X}_{\mathrm{ABG}}$ and from $\mathrm{X}_{\mathrm{GUA}}$ and $X_{K N Y}$ are negative during the main phase, consistent with the EEJ at Tirunelveli analyzed by Singh and Sripathi (2017) and the EEJ in Thailand (Astafyeva et al. 2018; Ngwira et al. 2019). Those results indicate that the westward EEJ is driven even in the nighttime ionosphere at the equator. The nightside EEJs of 30-40 nT are weaker than the dayside EEJ by one order of magnitude, being consistent with the result in Tsuji et al. (2012). It should be noted that the nightside EEJ is not very sensitive to the overshielding electric field associated with the northward turning of the IMF. The similarity in the temporal variations of the day- and night-side EEJs with opposite polarity implies that the EEJs are caused by the dawn-to-dusk penetration electric fields associated with the Region-1 FACs.

\section{$\mathrm{X}$ - and Y-component of the magnetic fields at middle latitudes}

In order to confirm that the EEJs are driven by the Region-1 FACs, we examine the correlation between the EEJs and the Y-component magnetic field at middle latitudes, which is caused by the Pedersen currents connecting the EEJ with the Region-1 FACs (Motoba et al. 2002 Hashimoto et al. 2011). The EEJ on the dayside would be positively correlated with the middle latitude Y-component in the morning sector, while the correlation is negative in the afternoon sector. Figure 3c shows $\mathrm{X}$ and $\mathrm{Y}$ at Honolulu $\left(\mathrm{X}_{\mathrm{HON}}, \mathrm{Y}_{\mathrm{HON}}\right)$ in the morning sector (09 MLT at $19 \mathrm{UT}$ ) and $\mathrm{X}$ and $\mathrm{Y}$ at Hartland ( $\mathrm{X}_{\mathrm{HAD}}$, $\mathrm{Y}_{\mathrm{HAD}}$ ) in the dusk sector (19 MLT). The $\mathrm{X}_{\mathrm{HON}}$ jumped by $50 \mathrm{nT}$ at the SC and monotonically decreased by $200 \mathrm{nT}$ after the SC until $1950 \mathrm{UT}$, whereas the $\mathrm{X}_{\mathrm{HAD}}$ remained almost constant with magnitude of about $200 \mathrm{nT}$. $\mathrm{X}_{\mathrm{HON}}$ is in the same shape as those at low latitudes, KNY and SJG, which indicates that the $\mathrm{X}$-component is overwhelmed by stormtime ring currents. $\mathrm{X}_{\mathrm{HAD}}$, on the other hand, is in a trapezoidal form similar to the EEJ at HUA, which indicates that the $\mathrm{X}$ is affected by afternoon/eveningtime DP2 currents flowing at middle latitudes during the storm main phase (Wilson et al. 2001). The strong local time asymmetry in the $\mathrm{X}$ may be associated with the high ASY-H index in Fig. 2b.

On the other hand, $\mathrm{Y}_{\mathrm{HON}}$ increased by $60 \mathrm{nT}$ from the pre-event level in the morning sector, while $\mathrm{Y}_{\mathrm{HAD}}$ decreased by $80 \mathrm{nT}$ in the evening sector during the storm main phase. It should be noted that the temporal variations of the Y-component are in a trapezoidal form similar to the EEJ and the correlation of $Y_{\mathrm{HON}}$ with the dayside EEJ is positive, while negative for $\mathrm{Y}_{\mathrm{HAD}}$ as predicted from the Pedersen currents flowing from the Region-1 FACs to the EEJs.

\section{HF Doppler observations of the electric field during the main phase}

The stormtime electric fields were observed by the HF Doppler sounders at middle and low latitudes in the western Pacific zone, Iitate, Oarai and Onna in Japan and Zhongli in Republic of China, and at middle latitude in the European zone, Prague in Czech Republic. Figure 4 shows electric fields converted from the HF Doppler frequency deviations using Eq. (1). The positive values represent the eastward electric field. When the SC occurred at 1833 UT, the westward electric field sharply increased at Iitate, Oarai, Onna and Zhongli in the post-midnight (0230-0330 MLT), reaching the maximum values within 3 min. The HF Doppler sounder at Prague, on the other hand, observed the eastward electric field in the evening (1930 MLT) that is in the same direction as the dayside EEJ at HUA. The evening-time electric fields have been reported to be in the same direction as in the day for the SC over Japan (Kikuchi et al. 1985, 2016) and DP2 fluctuation events at the equator (Abdu et al. 1998). The eastward electric field at Prague is indicative of the evening anomaly for the geomagnetic storm main phase. If the evening anomaly is a common property of the penetration electric field (Fejer et al. 2008), it is reasonable to expect eastward electric fields at Prague.

With regard to the intensity of the electric field during the storm main phase, the westward electric field decreases with decreasing latitude to be $3.7 \mathrm{mV} / \mathrm{m}$ at

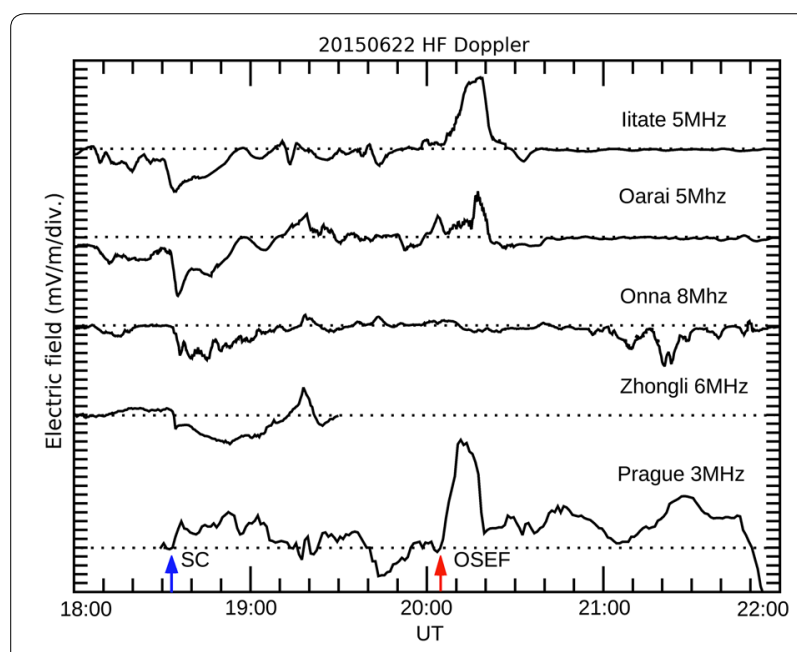

Fig. 4 Electric fields observed with the HF Doppler sounders in the western Pacific zone; litate, Oarai, Onna, Japan, and Zhongli, Republic of China, in the post-midnight (03-06 MLT) and in the Europe zone; Prague, Czech Republic in the evening (19-22 MLT). The electric field is positive/eastward. OSEF refers to the overshielding electric field 
Iitate, $5.1 \mathrm{mV} / \mathrm{m}$ at Oarai, $3.1 \mathrm{mV} / \mathrm{m}$ at Onna, $2.4 \mathrm{mV} / \mathrm{m}$ at Zhongli from the pre-event level. Figure 5 (red circles) shows latitudinal profiles of the intensity of the convection electric field at 1836 UT during the main phase, where the positive value refers to the eastward electric field. The electric field of $3.0 \mathrm{mV} / \mathrm{m}$ at Prague was less than that at Iitate despite the higher magnetic latitude of $50.2^{\circ}$ at Prague. The electric field may have been suppressed by the higher conductivity in the ionosphere over Prague that is sunlit at 1930 MLT in the summer solstice. The simultaneity with the EEJs (Fig. 3) and the latitudinal dependence of the westward electric field (red circles in Fig. 5) indicate that the storm time convection electric fields are transmitted from high latitude to the equator via the middle and low latitude ionosphere on both the day- and night-sides.

It should be stressed that the eastward electric field at Prague is consistent with the positive EEJ at HUA (Fig. 3a) and that the westward electric field at Iitate is consistent with the negative EEJ at GUA and TIR (Fig. 3b), although the duration times of the electric field are shorter than those of the EEJs. The westward electric field in Japan (e.g., Iitate) decreases gradually over $30 \mathrm{~min}$, while the westward EEJ at GUA remains constant in a trapezoidal form during the whole period of the main phase (Fig. 3b). This fact suggests that the reflection height of the HF radio signal tends to cease increasing even under the steady electric field, probably because of the reconfiguration of the F-region ionizations through the production and loss processes (Tsutsui et al. 1988). The time constant of the apparent decay of the electric field remains an issue to be solved in using the HF Doppler sounders as a detector of the stormtime electric field.

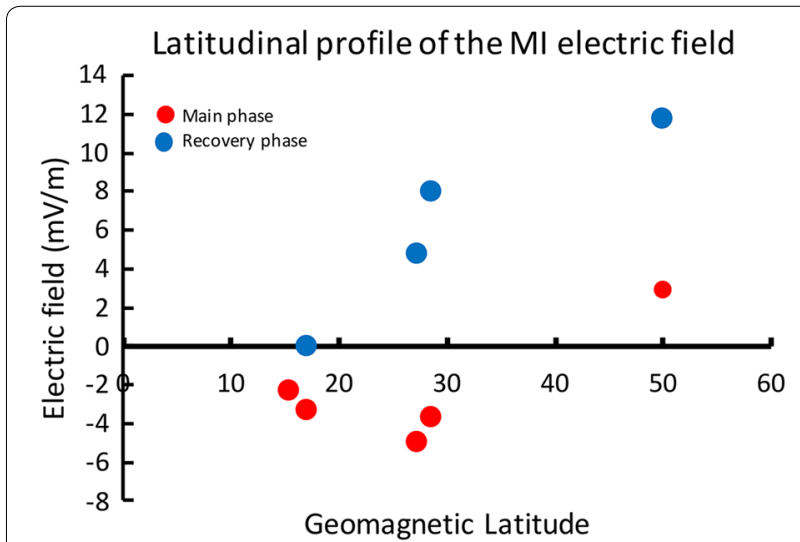

Fig. 5 Latitude profile of the main phase electric field (red) and overshielding electric field (blue). The main phase electric field is negative in the night, while positive in the evening. The overshielding electric field is positive at all stations located in the night

\section{Overshielding electric field during the storm recovery phase}

In the end of the main phase, the day- and night-side EEJs decreased over the period 1950-2010 UT (Fig. 3). The dayside EEJ turned into the CEJ at HUA because of the northward turning of the IMF (Fig. 3a), while no significant changes are observed on the nightside during the dayside CEJ (Fig. 3b). It is remarkable that the HF Doppler sounders detected impulsive eastward electric fields at Iitate, Oarai (0500 MLT) and Prague (2300 MLT) for about 17 min after 2005 UT (Fig. 4) during the northward IMF-driven CEJ. Figure 5 (blue) shows the intensity of the impulsive electric field at 2014 UT; 8.0, 4.8 and $11.8 \mathrm{mV} / \mathrm{m}$ at litate, Oarai and Prague, respectively, as measured from the values at the start of the impulsive electric field (2005UT). The impulsive electric field is eastward at all the stations located on the nightside (23-05 MLT), indicating that the electric field is associated with the overshielding during the period of the northward IMF-driven CEJ. It should be noted that the impulsive features are not observed in the EEJs on the nightside as well as on the dayside (Fig. 3a, b). To confirm the impulsive electric field be the overshielding electric field, we examined SuperDARN data in the following section.

\section{SuperDARN observation of the stormtime electric field}

Figure 6 shows the line of sight (LOS) velocity map constructed with two SuperDARN radars in north America and two radars in Japan looking at the auroral and subauroral latitudes on the dayside (12 MLT to the top) at 1940 UT during the main phase (upper panel) and 2014 UT during the impulsive electric field event (lower panel). The LOS velocity maps are drawn by using on-line plotting tools from the Virginia Tech website (http://vt.superdarn.org/). The LOS velocity toward the radar (anti-sunward) is shown in blue and green and away from the radar (sunward) in red color. The upper panel shows the large-scale two-cell convection with sunward flows in the 12-16 MLT sector during the main phase, which is typical for the southward IMF condition (Ruohoniemi and Greenwald 1996). The lower panel shows that the anti-sunward flow (green) appeared at $50^{\circ}-60^{\circ}$ GML equatorward of the sunward convection in the 12-13 MLT that indicates sudden intensification of the southward electric field, which must be provided by the Region-2 FACs (Hashimoto et al. 2011). To show temporal variations of the antisunward flow, we plotted the LOS velocity as a function of time as well as the radar echo intensity detected by the beam 9 of the Blackstone radar in the bottom and upper panels of Fig. 7, respectively. The antisunward plasma flow was observed during the period 


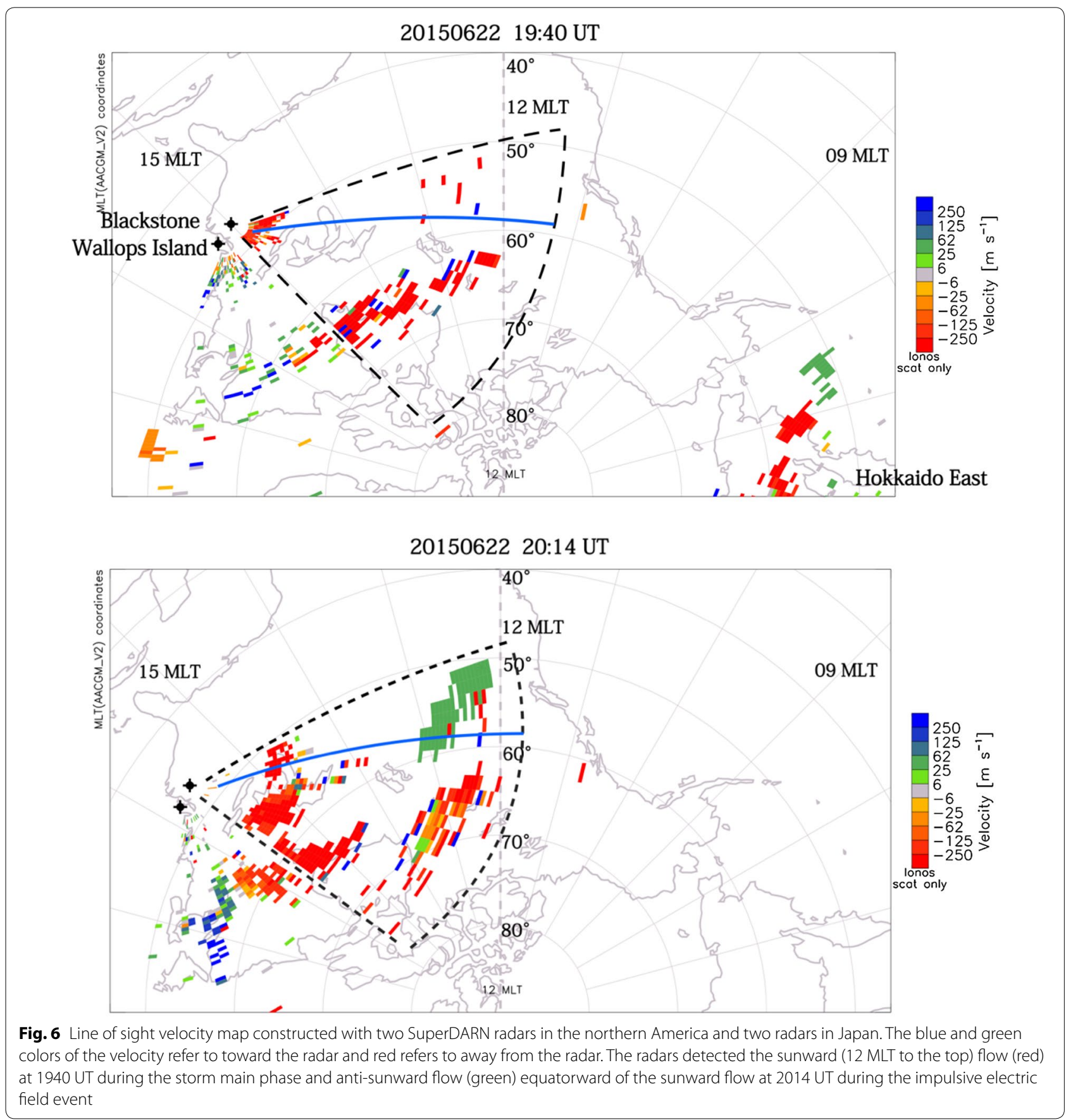

of 2008-2020 UT (green in the bottom panel) with velocity of $50-100 \mathrm{~m} / \mathrm{s}$, concurrently with the impulsive overshielding event observed by the HF Doppler sounder at middle latitudes. The beam 9 was looking at the anti-sunward plasma flow at subauroral latitudes $\left(58.6^{\circ}-59.1^{\circ} \mathrm{GML}\right)$ and in the post-noon sector $(1245-$ 1310 MLT).

\section{Discussion}

Evening anomaly of the main phase electric field

We have shown the stormtime electric fields at middle and low latitudes in the evening and night (Fig. 4), assuming that the electric field is in linear correlation with the HF Doppler frequency through Eq. (1). Although the linearity breaks down for long lasting electric fields, the 


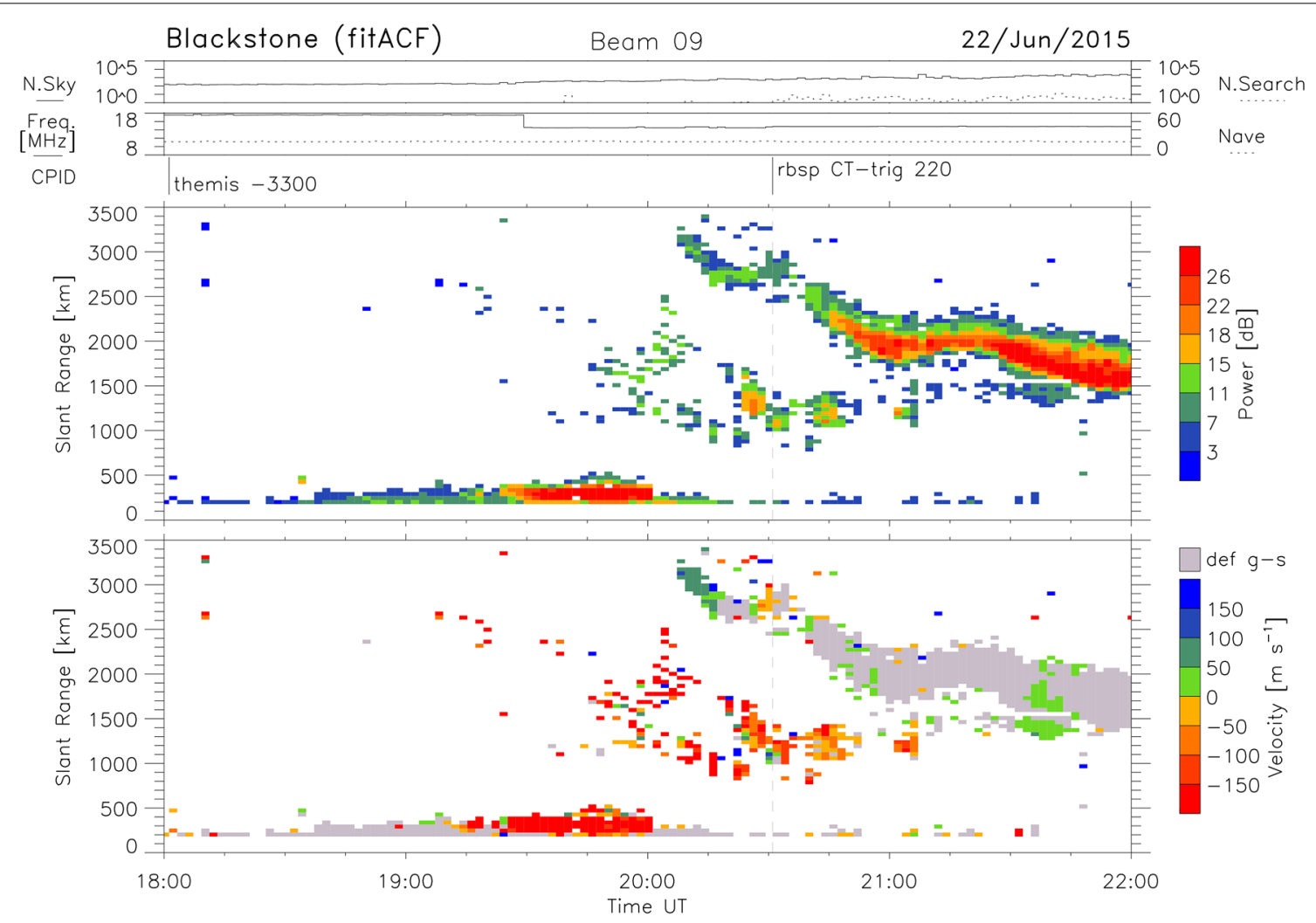

Fig. 7 Range-time plots of the echo power (upper panel) and line of sight velocity (lower panel) measured by the beam 09 of the Blackstone SuperDARN radar. The radar detected the anti-sunward flows (green) during the period of the impulsive electric field event

main phase electric field at Prague in the evening (19302010 MLT) has the eastward polarity same as the eastward EEJ at HUA on the dayside (Fig. 3a). On the other hand, the electric fields over Japan and EEJs at TIR and GUA were westward at the post-midnight (Fig. 3b). Cherniak and Zakharenkova (2016) reported intense plasma bubbles over Europe in the evening that should have been caused by the eastward electric field during the main phase of the 22 June storm that we report in the present paper. The eastward electric field has been known to cause ionospheric disturbances in the evening sector (e.g., Basu et al. 2001). The asymmetric local time features with the evening anomaly has been observed by the HF Doppler sounders during the SC (Kikuchi et al. 1985, 2016) and DP2 (Abdu et al. 1998) and by spacecrafts during quiet and disturbed periods (Fejer et al. 2008; Huang et al. 2010). The evening anomaly results from the distorted potential distribution caused by the day-night inhomogeneity and Hall effects of the ionospheric conductance (Senior and Blanc 1984; Tsunomura 1999).

At latitudes lower than $30^{\circ}$, the intensity of the convection electric field decreases with decreasing latitude such that $5.1 \mathrm{mV} / \mathrm{m}$ at middle latitude (Oarai) is twice stronger than $2.4 \mathrm{mV} / \mathrm{m}$ at low latitude (Zhongli) (red circles in Fig. 5). On the other hand, the evening-time electric field over Prague is $3.0 \mathrm{mV} / \mathrm{m}$, which is not subject to the evening enhancement, but is comparable to the intensity at Onna in the night. This feature can be explained with high ionospheric conductivity under sunlit conditions of the ionosphere at Prague in the summer solstice, which may have suppressed the convection electric field. These results lead us to conclude that the evening anomaly of the stormtime electric field expanded to 20 MLT, consistent with that of the SC (Kikuchi et al. 1985).

We have shown that the main phase electric field converted from the HF Doppler frequency deviations decreased monotonically over 30-40 min (Fig. 4), although the EEJ remained almost constant over $90 \mathrm{~min}$ during the whole period of the main phase on both the day- and night-sides (Fig. 3a, b). These facts suggest that the production-loss processes in the ionospheric F-region tend to reduce the upward velocity of the reflection height of the HF radio waves, so that the Doppler frequency decreases with time even under a constant electric field driving the motion of plasma (Tsutsui et al. 1988). If we had an incoherent scatter radar, we would have a linear correlation between the electric field and EEJ like those obtained by Anderson et al. (2002) with the 
incoherent scatter radar and magnetometer at Jicamarca. The quantitative relationship between the electric field derived from the HF Doppler sounder and the EEJ would help establish the HF Doppler sounder system as a tool of the electric field measurement, if we cover the effects of the disequilibrium of the ionization due to the production and loss processes.

\section{Impulsive overshielding electric field during the recovery phase}

As shown in Fig. 4, the HF Doppler sounders observed the prominent overshielding electric field for $17 \mathrm{~min}$ during the northward IMF-driven CEJ in the beginning of the recovery phase (2005 UT). The impulsive electric field is eastward both at Prague (2100 MLT) and Iitate (0500 MLT) that is opposite to the convection electric field. The blue circles in Fig. 5 represent the intensity of the electric field derived from four HF Doppler sounders except for Zhongli. The intensities of $11.8 \mathrm{mV} / \mathrm{m}$ at Prague and $8.0 \mathrm{mV} / \mathrm{m}$ at Iitate on the nightside were anomalously strong as compared with a few $\mathrm{mV} / \mathrm{m}$ of isolated substorms (Hashimoto et al. 2017). Furthermore, the overshielding electric field is more intense than the main phase convection electric field (red circles in Fig. 5) and decreases with decreasing latitude steeply to be almost zero at low latitude (Onna).

The latitude dependence of the overshielding electric field might be due to coupled effects of the decaying Region-1 FACs and growing Region-2 FACs in the transition period from the main phase to the recovery phase. The disturbance dynamo produces significant reversed electric fields at low latitude (Blanc and Richmond 1980). However, the duration (17 min) of the impulsive electric field is too short and the shape is too impulsive for the disturbance dynamo electric field that usually continues for several hours and sometimes may exceed $10 \mathrm{~h}$ (e.g., Zhang et al. 2017)

Another possible cause of the short-lasting overshielding electric field is an intensification of the Region-2 FACs during the substorm expansion (Tanaka et al. 2010; Hashimoto et al. 2011, 2017). Hashimoto et al. (2017) showed that when the substorm expansion breaks out, the equatorial counterelectrojet often develops on the dayside with sudden increases in the eastward electric field on the nightside and recovers to the pre-event level in 20-30 min. In addition, westward ionospheric currents and anti-sunward plasma flows are often intensified at subauroral latitudes together with the intensification of the eastward currents at the auroral latitudes in the afternoon sector (Hashimoto et al. 2011). As shown in Fig. 6, both the anti-sunward plasma flow at the subauroral latitude and the sunward flow at the auroral latitude as detected by SuperDARN strongly support that the downward Region-2 FACs had developed at the poleward edge of the anti-sunward flow region concurrently with the impulsive overshielding electric field at middle latitudes.

To verify that the impulsive overshielding is associated with the substorm, we examined the auroral electrojet indices (AU, AL) and magnetic $\mathrm{H}$-components at auroral latitudes, Dixon (DIK, 69.06 GML, 02 MLT) and Pebek (PBK, 65.58 ${ }^{\circ}$ GML, 07 MLT) in Fig. 8a, b. The westward AEJ at PBK started to intensify at 1833 UT and both the $\mathrm{AU}$ and $\mathrm{AL}$ indices enhanced, representing development of the convection electric field during the storm main phase. No appearance of the AEJ at DIK may be due to equatorward shift of the AEJ during the storm main phase (Feldstein et al. 1997; Kikuchi et al. 2008). When the IMF turned northward, the AEJ retreated to the normal auroral latitudes and caused the rapid increase in $\mathrm{AU}$ at 1955 UT. In the beginning of the recovery phase, the westward AEJ at DIK and PBK started to increase at 2005 UT concurrently with the decrease in the AL, reaching the minimum of $-1300 \mathrm{nT}$ at 2010 UT. The intensification of the westward AEJs and AL index signifies the onset of substorm (Wiens and Rostoker 1975), starting exactly at the same time as the impulsive overshielding electric field.

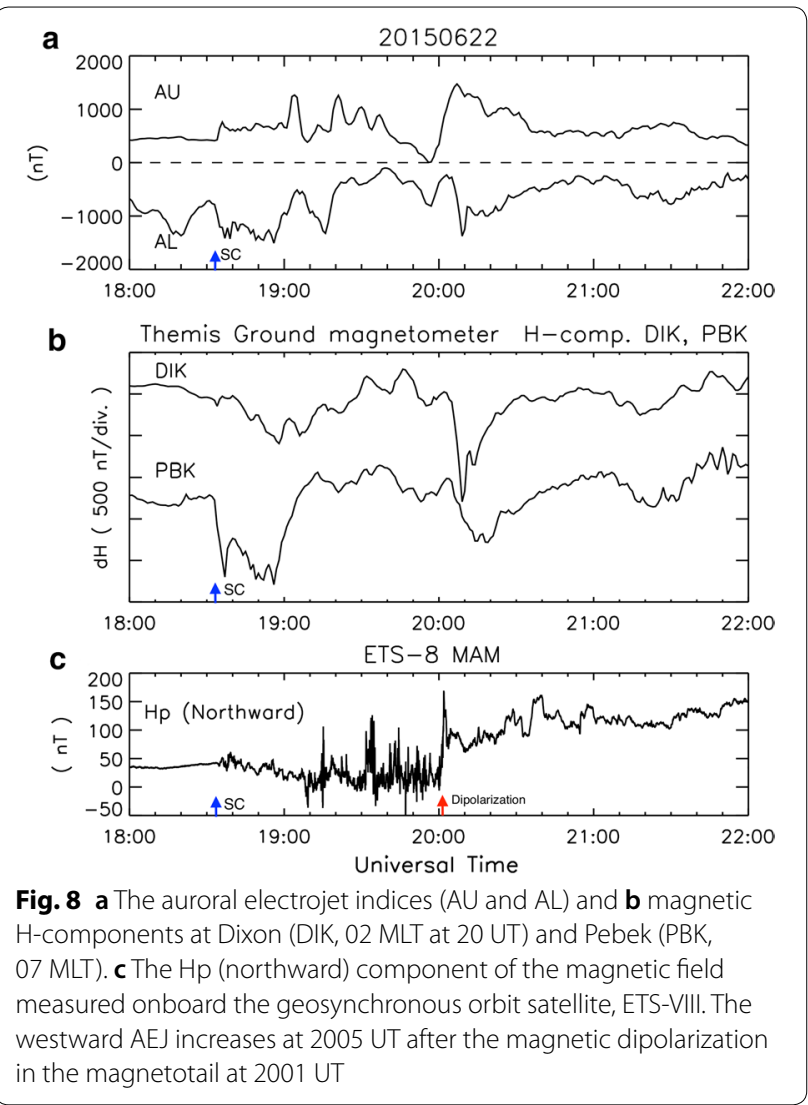


To ensure the occurrence of the substorm expansion, we further examined a signature of dipolarization of the near-Earth magnetotail magnetic field detected by the Engineering Test Satellite (ETS)-VIII geosynchronous satellite. It is well established that the magnetotail magnetic field in the geosynchronous orbit significantly changes from a taillike configuration to a dipolar configuration as the substorm progresses from the growth phase to the expansion phase (Cumming et al. 1968; McPherron et al. 1973; Kokubun and McPherron 1981). The configuration change of the magnetic field at the substorm expansion onset is called the dipolarization of the near-Earth magnetotail, which has been explained as resulting from diversion of the well-developed cross-tail current into the polar ionosphere (e.g., McPherron et al. 1973; Lui 1978). Consequently, the intensification of the AEJ at a substorm onset is closely related with the dipolarization of the magnetic field in the geosynchronous orbit (Lopez and Rosenvinge 1993).

ETS-VIII is an advanced technology demonstration satellite that JAXA launched on 18 December, 2006 and placed in a geosynchronous orbit at $146^{\circ} \mathrm{E}$ geographic longitude over the western Pacific. The onboard triaxial fluxgate magnetometer (MAM) observations provide us with signatures of the substorm, i.e., dipolarization of the tail magnetic field (Nose et al. 2014). The Hp (northward) component of MAM is plotted for the 22 June storm in Fig. 8c, which has been corrected in accordance with the Appendix A of Nose et al. (2014).

The Hp gradually decreased with short-term fluctuations as the convection electric field developed during the storm main phase and then substantially jumped up by more than $150 \mathrm{nT}$ at $2001 \mathrm{UT}$, a few minutes earlier than the onset of the overshielding in the ionosphere. Figure 9 shows zoomed in plots of $\mathrm{Hp}$ and $\mathrm{He}$ (Earthward) at around the tail magnetic dipolarization. The He component decreases sharply at 20:01:35 UT (vertical dotted line) concurrently with the increase in Hp. The temporal variations of $\mathrm{Hp}$ and $\mathrm{He}$ match the configuration change from stretched to dipolarized forms. The drastic changes over a few minutes in the near-Earth magnetotail may be associated with the impulsive feature of the overshielding electric field. In spite of the predawn sector of 05 MLT, the magnetic field reconfiguration observed by the ETSVIII is consistent with the dipolarization signatures in the premidnight hours (Lopez and Rosenvinge 1993; Ohtani et al. 1992; Liou et al. 2002).

The time difference of several minutes between the dipolarization and overshielding may be the time needed for activation of the Region-2 FACs dynamo in the nearEarth magnetotail and propagation from the dynamo to the polar ionosphere. Note that the propagation from the polar ionosphere to low latitude is near-instantaneous by

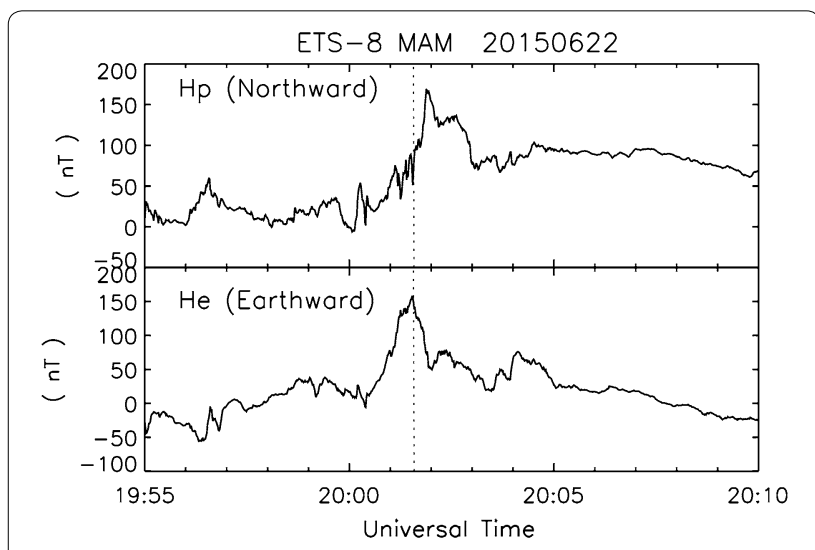

Fig. 9 Zoomed in plots of $\mathrm{Hp}$ and He (Earthward) at around the tail magnetic dipolarization. The rapid decrease in He (dotted line) occurs concurrently with the rapid increase in $\mathrm{Hp}$, which signifies a reconfiguration of the tail magnetic field at the onset of substorm

the $\mathrm{TM}_{0}$ mode wave in the Earth-ionosphere waveguide (Kikuchi and Araki 1979). On the basis of these results, we conclude that the impulsive eastward electric field on the nightside is most likely to be the substorm overshielding electric field found by Hashimoto et al. (2017).

The overshielding electric field detected simultaneously at Prague, Iitate and Oarai shows global penetration of the electric field, which leads us to expect an impulsive EEJ/ CEJ, but we did not see clear signatures as in Fig. 3. As shown in Fig. 5, the overshielding electric field decreases with decreasing latitude steeply to be almost zero at low latitude. The overshielding electric field associated with the Region-2 FACs competes against the convection electric field associated with the Region-1 FACs at the low and equatorial latitudes (Kikuchi 2000; Peymirat et al. 2000; Hashimoto et al. 2011, 2017). Hashimoto et al. (2011) showed that both the Region-1 and Region-2 FACs are intensified during the substorm expansion and that the overshielding electric field often overcomes the convection electric field at low latitudes during isolated substorms. In the storm event, the Region-1 FACs have a large spatial scale extending to middle latitudes and make significant effects at the equator (Kikuchi et al. 2008). If the impulsive overshielding electric field is associated with the substorm, the Region-2 FACs must have a smaller scale extending further equatorward, closer to the HF Doppler sounders at middle latitudes. In this situation, it is likely that the overshielding electric field suffers much severer geometrical attenuation than the convection electric field during its propagation to the equator (Kikuchi and Araki 1979). The severe geometrical attenuation would cause the steep latitudinal profile of the overshielding electric field in Fig. 5 and no significant effects at the 
equator. This scenario should be verified with model calculations in the future works. field to the middle latitude ionosphere on the nightside.

\section{Conclusion}

1. Using the HF Doppler sounders at middle and low latitudes and magnetometers at the low and equatorial latitudes, we found that stormtime electric fields penetrated promptly on both the day- and nightsides during the geomagnetic storm on 22 June, 2015.

2. The HF Doppler sounders at Prague, Czech Republic (1930 MLT), Iitate, Oarai, Onna, Japan (0330 MLT) and Zhongli, Republic of China (0230 MLT) successfully detected the eastward electric field in the evening and westward electric field in the night during the storm main phase. The eastward electric field at Prague indicates the evening anomaly of the penetration electric field with the direction same as on the day, which must have caused severe ionospheric disturbances over Europe reported by several other papers.

3. The main phase electric field caused DP2 currents at middle-equatorial latitudes, driving eastward and westward EEJs on the day- and night-sides, respectively. The Y-component magnetic field at middle latitudes detected north-south ionospheric currents connecting the EEJs with the Region-1 FACs developed by the southward IMF.

4. The HF Doppler sounders detected the anomalously strong eastward overshielding electric fields $(8.0 \mathrm{mV} / \mathrm{m}$ at Iitate and $11.8 \mathrm{mV} / \mathrm{m}$ at Prague $)$ on the nightside for $17 \mathrm{~min}$ in the beginning of the recovery phase of the storm. The overshielding electric field decreases with decreasing latitude steeply to be zero at low latitude, consistent with no corresponding changes in the EEJ at the equator.

5. The Blackstone SuperDARN radar in the American sector observed anti-sunward plasma flow equatorward of the normal sunward plasma flow during the period of the overshielding electric field, which may indicate development of the Region-2 FACs equatorward of the Region-1 FACs.

6. The impulsive overshielding electric field was found to be associated with substorm signatures; intensification of the westward auroral electrojets on the nightside and dipolarization of the tail magnetic field as detected by the geosynchronous satellite, ETSVIII.

7. In conclusion, the stormtime convection electric field penetrated to the middle and low latitudes during the main phase, and the stormtime substorm may play a crucial role in providing strong overshielding electric

\section{Abbreviations}

AEJ: Auroral electrojet; CEJ: Counter electrojet; EEJ: Equatorial electrojet; FAC: Field-aligned current; GML: Geomagnetic latitude; HF: High frequency; IMF: Interplanetary magnetic field; IonN: Ion density; LOS: Line of sight; MLT: Magnetic local time; SC: Sudden commencement; UT: Universal time; Vsw: Solar wind velocity.

\section{Acknowledgements}

The results presented in this paper rely on the data collected at Guam, Hartland, Honolulu, Huancayo, Kanoya and San Juan. We thank United States Geological Survey, British Geological survey, Instituto Geofisico del Peru, and Japan Meteorological Agency for supporting its operation and INTERMAGNET for promoting high standards of magnetic observatory practice (http://www.inter magnet.org). The AE index and ASY and SYM indices used in this paper was provided by the WDC for Geomagnetism, Kyoto (http://wdc.kugi.kyoto-u.ac. jp/wdc/Sec3.html). The ACE solar wind data and THEMIS ground-based magnetometer data at Dixon and Pebek were obtained through the Coordinated Data Analysis Web (CDAWeb; http://cdaweb.gsfc.nasa.gov/). We acknowledge NASA contract NAS5-02099 and V. Angelopoulos for use of data from the THEMIS Mission. Specifically, we acknowledge Arctic and Antarctic Research Institute (AARI), Department of Geophysics (http://geophys.aari.ru) for use of Dixon and Pebek magnetometer data.The authors acknowledge the use of SuperDARN data. SuperDARN is a collection of radars funded by national scientific funding agencies of Australia, Canada, China, France, Italy, Japan, Norway, South Africa, United Kingdom and the United States of America. We acknowledge the use of the on-line plotting tools hosted by the Virginia Tech SuperDARN group at their website (http://vt.superdarn.org). Magnetometer data at Alibag and Tirunelveli were downloaded from SuperMag (http://super mag.jhuapl.edu/mag/). For the ground magnetometer data we gratefully acknowledge: Pushkov Institute of Terrestrial Magnetism, lonosphere and Radio Wave Propagation (IZMIRAN); GFZ, PI Dr. Juergen Matzka; MAGDAS, PI K. Yumoto; data obtained in cooperation with Geoscience Australia, PI Marina Costelloe; SuperMAG, PI Jesper W. Gjerloev. A part of this study was carried by using the Space Environment data distributed from JAXA/SEES.

\section{Authors' contributions}

KKH contributed to the design and implementation of the study, to the analysis of the results and to the writing of the initial draft of the manuscript. TK contributed to interpretation of data and assisted in the preparation of the manuscript. IT and KH performed observations with HF Doppler sounders in Japan. JC and DB performed observations with HF Doppler sounders at Prague and Zhongli. MN contributed to calibration of the magnetometer data onboard the ETS-VIII satellite. KK performed collection of the magnetometer data onboard the ETS-VIII satellite. All authors read and approved the final manuscript.

\section{Funding}

The works of KKH and TK are supported by the JSPS KAKENHI Grant Numbers JP22540461 and JP26400481 and the joint research program of the National Institute of Polar Research, Tokyo (Grant Number 30-5, 2-9). The works of IT, KH, KKH and TK are supported by Hoso Bunka Foundation. The study of TK is supported by the grants-in-aid for Scientific Research (15H05815) of Japan Society for the Promotion of Science (JSPS) and the joint research programs of the Institute for Space-Earth Environmental Research, Nagoya University, and the KDK of the Research Institute for Sustainable Humanosphere, Kyoto University (Grant Number: 30KDK-10). The work of KH is supported by the Takahashi Industrial and Economic Research Foundation (Grant Number: 10-003-016). 


\section{Availability of data and materials}

(1) ETS-VIII MAM data: Japan Aerospace Exploration Agency (JAXA), Space Environment \& Effects System (http://sees.tksc.jaxa.jp/fw/dfw/SEES/Japanese/ Data/docs_ja/ETS8/ETS8_DataGraph.htm). (2) Geomagnetic indices: World Data Center C2 in Kyoto (http://wdc.kugi.kyoto-u.ac.jp/wdc/Sec3.html). (3) HF Doppler: HF Doppler Sounding Experiment in Japan-HFDOPE (http://gwave cei.uec.ac.jp/ hfd/). (4) Magnetometer data: INTERMAGNET website (http:// www.intermagnet.org). (5) Magnetometer data: SuperMAG website (http:// supermag.jhuapl.edu). (6) Solar wind data of the ACE satellite and THEMIS ground magnetometer data: Coordinated Data Analysis Web (https://cdawe b.sci.gsfc.nasa.gov). (7) SuperDARN radar: Virginia Tech SuperDARN group (http://vt.superdarn.org/).

\section{Ethics approval and consent to participate}

Not applicable.

\section{Consent for publication}

Not applicable.

\section{Competing interests}

The authors declare that they have no competing interests

\section{Author details}

1 School of Agriculture, Kibi International University, 370-1, Shichi-Sareo, Minamiawaji, Hyogo, Japan. ${ }^{2}$ Institute for Space-Earth Environmental Research, Nagoya University, Furo-cho, Chikusa-ku, Nagoya, Japan. ${ }^{3}$ Center for Space Science and Radio Engineering, The University of Electro-Communications, 1-5-1 Chofugaoka, Chofu, Tokyo 182-8585, Japan. ${ }^{4}$ Department of Communication Engineering and Informatics, The University of Electro-Communications, 1-5-1 Chofugaoka, Chofu, Tokyo 182-8585, Japan. ${ }^{5}$ Department of the lonosphere and Aeronomy, Institute of Atmospheric Physics of the Czech Academy of Sciences, Prague, Czech Republic. ${ }^{6}$ Research and Development Directorate, Japan Aerospace Exploration Agency, Tsukuba, Japan.

Received: 7 October 2019 Accepted: 16 May 2020

Published online: 26 May 2020

\section{References}

Abdu MA, Sastri JH, Luhr H, Tachihara H, Kitamura T, Trivedi NB, Sobral JHA (1998) DP 2 electric field fluctuations in the dusk-time dip equatorial ionosphere. Geophys Res Lett 25:9. https://doi.org/10.1029/98GL01096

Alperovich LS, Fedorov EN, Volgin AV, Pokhil'ko SV, Leus LA, Pilipenko VA, Karpov PN (1991) Doppler sounding as tool for the study of MHD wave structure in the ionosphere. J Atmos Terr Phys 53:581-586

Anderson DN, Anghel A, Yumoto K, Ishitsuka M, Kudeki E (2002) Estimating daytime vertical ExB drift velocities in the equatorial F-region using ground-based magnetometer observations. Geophys Res Lett 29(12):1596. https://doi.org/10.1029/2001GL014562

Astafyeva E, Zakharenkova I, Alken P (2016) Prompt penetration electric fields and the extreme topside ionospheric response to the June 22-23, 2015 geomagnetic storm as seen by the Swarm constellation. Earth Planets Space 68:152. https://doi.org/10.1186/s40623-016-0526-x

Astafyeva E, Zakharenkova I, Huba JD, Doornbos E, ljssel VD Jr (2017) Global ionospheric and thermospheric effects of the June 2015 geomagnetic disturbances: multi-instrumental observations and modeling. J Geophys Res 122:11716-11742. https://doi.org/10.1002/2017JA024174

Astafyeva E, Zakharenkova I, Hozumi K, Alken P, Coïsson P, Hairston MR, Coley WR (2018) Study of the equatorial and low-latitude electrodynamic and ionospheric disturbances during the 22-23 June 2015 geomagnetic storm using ground-based and space-borne techniques. J Geophys Res 123(3):2424-2440. https://doi.org/10.1002/2017JA024981

Baddeley LJ, Yeoman TK, Wright DM (2005) HF doppler sounder measurements of the ionospheric signatures of small scale ULF waves. Ann Geophys 23:1807-1820

Basu S, Basu S, Groves KM, Yeh HC, Su SY, Rich FJ et al. (2001) Response of the equatorial ionosphere in the South Atlantic region to the great magnetic storm of July 15, 2000. Geophys Res Lett 28(18):3577-3580. https://doi. org/10.1029/2001GL013259
Blanc M, Richmond AD (1980) The ionospheric disturbance dynamo. J Geophys Res 85:1669-1686

Blanc M, Amayenc P, Bauer P, Taieb C (1977) Electric field induced drifts from the French incoherent scatter facility. J Geophys Res 82:87-97

Burke WJ, Rubin AG, Maynard NC, Gentile LC, Sultan PJ, Rich FJ, de La Beaujardiere O, Huang CY, Wilson GR (2000) lonospheric disturbances observed by DMSP at middle to low latitudes during the magnetic storm of June 4-6, 1991. J Geophys Res 105:18391-18405

Cherniak I, Zakharenkova I (2016) First observations of super plasma bubbles in Europe. Geophys Res Lett 43:11137-11145. https://doi. org/10.1002/2016GL071421

Cherniak I, Zakharenkova I, Sokolovsky S (2019) Multi-instrumental observation of storm-induced ionospheric plasma bubbles at equatorial and middle latitudes. J Geophys Res Space Phys 124:1491-1508. https://doi. org/10.1029/2018JA026309

Chum J, Liu J-Y, Podolská K, Šindelářová T (2018) Infrasound in the ionosphere from earthquakes and typhoons. J Atmos Sol Terr Phys 171:72-82. https //doi.org/10.1016/j.jastp.2017.07.022

Cumming WD, Barfield JN, Coleman PJ Jr (1968) Magnetospheric substorms observed at the synchronous orbit. J Geophys Res 73(21):6687-6698

Davies K, Watts JM, Zacharisen DH (1962) A study of F2-layer effects as observed with a Doppler technique. J Geophys Res 67:601-609

Ebihara Y, Ejiri M (2000) Simulation study on fundamental properties of the storm-time ring current. J Geophys Res 105:15843-15859

Fejer BG, Jensen JW, Kikuchi T, Abdu MA, Chau JL (2007) Equatorial ionospheric electric fields during the November 2004 magnetic storm. J Geophys Res 112:A10304. https://doi.org/10.1029/2007JA012376

Fejer BG, Jensen JW, Su S-Y (2008) Seasonal and longitudinal dependence of equatorial disturbance vertical plasma drifts. Geophys Res Lett 35:L20106. https://doi.org/10.1029/2008GL035584

Feldstein YI, Grafe A, Gromova LI, Popov VA (1997) Auroral electrojets during geomagnetic storms. J Geophys Res 102(A7):14223-14235

Gjerloev JW (2012) The SuperMAG data processing technique. J Geophys Res 117:A09213. https://doi.org/10.1029/2012JA017683

Hashimoto KK, Kikuchi T, Watari S, Abdu MA (2011) Polar-equatorial ionospheric currents driven by the region 2 field-aligned currents at the onset of substorms. J Geophys Res 116:A09217. https://doi.org/10.1029/2011 J A016442

Hashimoto KK, Kikuchi T, Tomizawa I, Nagatsuma T (2017) Substorm overshielding electric field at low latitude on the nightside as observed by the HF Doppler sounder and magnetometers. J Geophys Res Space Phys. https://doi.org/10.1002/2017JA024329

Hirono M (1952) A theory of diurnal magnetic variations in equatorial regions and conductivity of the ionosphere E region. J Geomagn Geoelectr Kyoto $4: 7-21$

Huang C-S (2015) Storm-to-storm main phase repeatability of the local time variation of disturbed low-latitude vertical ion drifts. Geophys Res Lett 42:5694-5701. https://doi.org/10.1002/2015GL064674

Huang C-S, Rich FJ, Burke WJ (2010) Storm time electric fields in the equatorial ionosphere observed near the dusk meridian. J Geophys Res 115:A08313. https://doi.org/10.1029/2009JA015150

Kelley MC, Fejer BG, Gonzales CA (1979) An explanation for anomalous equatorial ionospheric electric fields associated with a northward turning of the interplanetary magnetic field. Geophys Res Lett 6:301-304

Kikuchi T (2014) Transmission line model for the near-instantaneous transmission of the ionospheric electric field and currents to the equator. J Geophys Res Space Phys. https://doi.org/10.1002/2013JA019515

Kikuchi T, Araki T (1979) Horizontal transmission of the polar electric field to the equator. J Atmos Terr Phys 41:927-936

Kikuchi T, Araki T, Maeda H, Maekawa K (1978) Transmission of polar electric fields to the equator. Nature 273:650-651

Kikuchi T, Ishimine T, Sugiuchi H (1985) Local time distribution of HF Doppler frequency deviations associated with storm sudden commencements. J Geophys Res 90:4389-4393

Kikuchi T, Lühr H, Kitamura T, Saka O, Schlegel K (1996) Direct penetration of the polar electric field to the equator during a DP2 event as detected by the auroral and equatorial magnetometer chains and the EISCAT radar. J Geophys Res 101:17161-17173

Kikuchi T, Luehr H, Schlegel K, Tachihara H, Shinohara M, Kitamura T-I (2000) Penetration of auroral electric fields to the equator during a substorm. $J$ Geophys Res 105(A10):23251-23261 
Kikuchi T, Hashimoto KK, Nozaki K (2008) Penetration of magnetospheric electric fields to the equator during a geomagnetic storm. J Geophys Res 113:A06214. https://doi.org/10.1029/2007JA012628

Kikuchi T, Hashimoto KK, Tomizawa I, Ebihara Y, Nishimura Y, Araki T, Shinbori A, Veenadhari B, Tanaka T, Nagatsuma T (2016) Response of the incompressible ionosphere to the compression of the magnetosphere during the geomagnetic sudden commencements. J Geophys Res Space Phys. https ://doi.org/10.1002/2015JA022166

Kil H, Oh S-J, Paxton LJ, Zhang Y, Su S-Y, Min K-W (2007) Spike-like change of the vertical $E \times B$ drift in the equatorial region during very large geomagnetic storms. Geophys Res Lett 34:L09103. https://doi.org/10.1029/2007G L029277

Kokubun S, McPherron RL (1981) Substorm signatures at synchronous altitude. J Geophys Res 86(A13):11265-11277

Laštovička J, Chum J (2017) A review of results of the international ionospheric Doppler sounder network. Adv Space Res 60:1629-1643. https://doi. org/10.1016/j.asr.2017.01.032

Liou K, Meng Cl, Lui AT, Newell PT, Wing S (2002) Magnetic dipolarization with substorm expansion onset. J Geophys Res 107(A7):1131. https://doi. org/10.1029/2001JA000179

Lopez RE, Rosenvinge TV (1993) A statistical relationship between the geosynchronous magnetic field and substorm electrojet magnitude. J Geophys Res 98(A3):3851-3857

Lui ATY (1978) Estimates of current changes in the geomagnetotail associated with a substorm. Geophys Res Lett 5(10):853-856

McPherron RL, Russell CT, Aubry MP (1973) Satellite studies of magnetospheric substorms on August 15, 1968, 9, phenomenological model for substorms. J Geophys Res 78(16):3131-3149

Motoba T, Kikuchi T, Lühr H, Tachihara H, Kitamura T-I, Hayashi K, Okuzawa T (2002) Global Pc5 caused by a DP2-type ionospheric current system. J Geophys Res 107:A2. https://doi.org/10.1029/2001JA900156

Motoba T, Kikuchi T, Fukuda TS, Yumoto K (2004) HF Doppler oscillations in the low-latitude ionosphere coherent with equatorial long-period geomagnetic field oscillations. J Geophys Res 109:A06214. https://doi. org/10.1029/2004JA010442

Ngwira CM, Habarulema JB, Astafyeva E, Yizengaw E, Jonah OF, Crowley G, Andrew G, Goffey V (2019) Dynamic response of ionospheric plasma density to the geomagnetic storm of 22-23 June 2015. J Geophys Res 124:7123-7139. https://doi.org/10.1029/2018JA026122

Nose M, Takahashi K, Keika K, Kistler LM, Koga K, Koshiishi H, Matsumoto H, Shoji M, Miyashita Y, Nomura R (2014) Magnetic fluctuations embedded in dipolarization inside geosynchronous orbit and their associated selective acceleration of O+ ions. J Geophys Res Space Phys. https://doi. org/10.1002/2014JA019806

Ohtani S, Takahashi K, Zanetti LJ, Potemra TA, McEntire RW, lijima T (1992) Initial signatures of magnetic field and energetic particle fluxes at tail reconfiguration: explosive growth phase. J Geophys Res 97(12):19311-19324

Peymirat C, Richmond AD, Kobea AT (2000) Electrodynamic coupling of high and low latitudes: simulations of shielding, overshielding effects. J Geophys Res 105:22991-23003

Piersanti M, Alberti T, Bemporad A, Berrilli F, Bruno R et al (2017) Comprehensive analysis of the geoeffective solar event of 21 June 2015: effects on the magnetosphere, plasmasphere, and ionosphere systems. Sol Phys 292:169. https://doi.org/10.1007/s11207-017-1186-0

Pilipenko VA, Fedorov EN, Teramoto M, Yumoto K (2013) The mechanism of mid-latitude Pi2 waves in the upper ionosphere as revealed by combined Doppler and magnetometer observations. Ann Geophys 31:689-695. https://doi.org/10.5194/angeo-31-689-2013

Rastogi RG (1977) Geomagnetic storms and electric fields in the equatorial ionosphere. Nature 268:422-424

Reddy CA, Ravindran S, Viswanathan KS, Murthy BVK, Rao DRK, Araki T (1994) Observations of Pc5 micropulsation-related electric field oscillations in the equatorial ionosphere. Ann Geophysicae 18:252-256
Ruohoniemi JM, Greenwald RA (1996) Statistical patterns of high-latitude convection obtained from Goose Bay HF radar observations. J Geophys Res 101(A10):21743-21763

Sastri JH, Luhr H, Tachihara H, Kitamura T-I, Rao JVSV (2000) Electric field fluctuations ( $25 \pm 35 \mathrm{~min}$ ) in the midnight dip equatorial ionosphere. Ann Geophysicae 18:252-256

Senior C, Blanc M (1984) On the control of magnetospheric convection by the spatial distribution of ionospheric conductivities. J Geophys Res 89:261-284

Singh R, Sripathi S (2017) lonospheric response to 22-23 June 2015 storm as investigated using ground-based ionosondes and GPS receivers over India. J Geophys Res 122:11645-11664. https://doi.org/10.1002/2017J A024460

Tanaka T (1995) Generation mechanisms for magnetosphere-ionosphere current systems deduced from a three-dimensional MHD simulation of the solar wind-magnetosphere-ionosphere coupling processes. J Geophys Res 100:12057-12074

Tanaka T (2007) Magnetosphere-ionosphere convection as a compound system. Space Sci Rev 133:1. https://doi.org/10.1007/s11214-007-9168-4

Tanaka T, Nakamizo A, Yoshikawa A, Fujita S, Shinagawa H, Shimazu H, Kikuchi T, Hashimoto KK (2010) Substorm convection and current system deduced from the global simulation. J Geophys Res 115:A05220. https:// doi.org/10.1029/2009JA014676

Tsuji Y, Shinbori A, Kikuchi T, Nagatsuma T (2012) Magnetic latitude and local time distributions of ionospheric currents during a geomagnetic storm. J Geophys Res 117:A07318. https://doi.org/10.1029/2012JA017566

Tsunomura S (1999) Numerical analysis of global ionospheric current system including the effect of equatorial enhancement. Ann Geophysicae 17:692-706

Tsutsui M, Ogawa T, Kamide Y, Kroehl HW, Hausman BA (1988) A method of estimating horizontal vectors of ionospheric electric field deduced from HF Doppler data. Radio Sci 23(2):119-128. https://doi.org/10.1029/RS023 i002p00119

Vasyliuna V (1972) The interrelationship of magnetospheric processes. In: McCormac BM (ed) Earth's magnetospheric processes, pp 29-38

Wei $Y$ et al (2009) Westward ionospheric electric field perturbations on the dayside associated with substorm processes. J Geophys Res 114:A12209. https://doi.org/10.1029/2009JA014445

Wiens RG, Rostoker G (1975) Characteristics of the development of the westward electrojet during the expansive phase of magnetospheric substorms. J Geophys Res 80:2109-2128

Wilson GR, Burke WJ, Maynard NC, Huang CY, Singer HJ (2001) Global electrodynamics observed during the initial and main phases of the July 1991 magnetic storm. J Geophys Res 106(A11):24517-24539

Zhang R, Liu L, Le H, Chen Y, Kuai J (2017) The storm time evolution of the ionospheric disturbance plasma drifts. J Geophys Res Space Phys 122:11665-11676. https://doi.org/10.1002/2017JA024637

\section{Publisher's Note}

Springer Nature remains neutral with regard to jurisdictional claims in published maps and institutional affiliations. 